\title{
DOSES DE ADUBACCÃO NITROGENADA EM COBERTURA SUBMETIDO A DOIS NÍVEIS DE DESFOLHA NO MILHO SAFRINHA NA AMAZÔNIA OCIDENTAL
}

Jhonny Kelvin Dias Martins ${ }^{1}$; Silvana Ramlow Otto Teixeira da Luz ${ }^{1}$; Cleidson Alves da Silva'; Claudemir Schanz Turcato ${ }^{1}$

1 Graduando (a) do curso de Agronomia, Fundação Universidade Federal de Rondônia - UNIR, (jhonny.jkdm@gmail.com) Rolim de Moura- Brasil

Recebido em: 15/04/2017 - Aprovado em: 22/07/2017 - Publicado em: 31/07/2017 DOI: 10.18677/Agrarian_Academy_2017a18

\begin{abstract}
RESUMO
A cultura do milho apresenta grande sensibilidade quando acometida por algum tipo de lesão ou estresse que possam reduzir a área foliar podendo afetar diretamente a produtividade, sendo que o nitrogênio é importante no metabolismo fotossintético na planta. Diante disso o trabalho foi instalado no município de Rolim de Moura-RO na Fundação universidade Federal de Rondônia (UNIR) no campus experimental km 15 , submetendo se a quatro doses de adubação nitrogenada (0,60, 120 e $240 \mathrm{~kg}$ ha $\left.^{-1}\right)$, usando como fonte de $\mathrm{N}$ ureia $(45 \% \mathrm{~N})$ e dois níveis de desfolha, remoção de $50 \%$ das folhas abaixo da espiga e remoção de $50 \%$ das folhas acima da espiga, de forma manual quando as plantas se encontravam no estádio VT, o delineamento experimental utilizado foi 0 de blocos casualizado em esquema fatorial $4 \times 2$, as variáveis analisadas foram: diâmetro da espiga, comprimento da espiga, número de fileira, número de grãos por fileira e produtividade. Observou-se que as doses crescentes de $\mathrm{N}$ foram significativas, exceto para o número de grãos por fileiras. Já para os nível de desfolha realizando acima da espiga obteve menor diâmetro de espigas e menor produtividade, 18,36 e $11,65 \%$ respectivamente comparadas a desfolha abaixo da espiga.
\end{abstract}

PALAVRAS-CHAVE: fertilizante, níveis, produção, Zea mays .

\section{NITROGEN FERTILIZATION DOSES IN COVERAGE SUBMITTED TO TWO LEVELS OF DESFOLHANE IN CORN SAFRINHA IN THE WESTERN AMAZO}

\begin{abstract}
The corn crop presents great sensitivity when caused by some type of injury or stresses that can reduce its leaf area and can directly affect the productivity, being the nitrogen is important in the photosynthetic metabolism in the plant. The work was installed in the municipality of Rolim de Moura-RO at the Federal University of Rondônia Foundation (UNIR) at the experimental campus km 15, submitted to four doses of nitrogen fertilization $\left(0,60,120\right.$ and $\left.240 \mathrm{~kg} \mathrm{ha}^{-1}\right)$, Using as a source of $\mathrm{N}$ urea $(45 \% \mathrm{~N})$ and two levels of defoliation, $50 \%$ removal of the leaves below the spike and removal of $50 \%$ of the leaves above the spike, manually when the plants were in the VT stage, The experimental design used was a randomized block design
\end{abstract}


in a $4 \times 2$ factorial scheme, the variables analyzed were: ear diameter, ear length, row number, number of grains per row and productivity. It was observed that increasing doses of $\mathrm{N}$ were significant, except for the number of grains per row. However, for the defoliation level above the spike, it obtained a smaller diameter of spikes and lower productivity, 18.36 and $11.65 \%$, respectively, compared to defoliation below the spike.

KEYWORDS: Production, fertilizer, levels, Zea mays

\section{INTRODUÇÃO}

O milho (Zea mays L.) desempenha papel fundamental na agricultura Brasileira tanto do ponto de vista econômico em função da extensa cadeia produtiva e por ser uma commódite em acessão no mercado internacional (BONO et al., 2008). A produtividade média atingiu 85 sacos ha ${ }^{-1}$ e gerou 84 milhões de toneladas no ano de 2016, com 56 milhões destinados ao consumo; 28 milhões de toneladas destinaram-se a exportação e 6,5 milhões a armazenagem (CONAB, 2016).

O milho apresenta alto potencial produtivo, e também grande sensibilidade a estresses que reduzam sua área foliar por possuir baixa plasticidade vegetativa (SANGOI et al., 2014a). De acordo com ALVIM et al. (2010) a redução da área foliar em plantas de milho altera a atividade fisiológica e consequentemente o rendimento de grãos. Danos causados por insetos-praga, como a lagarta-do-cartucho (Spodoptera frugiperda), por doenças e por intempéries climáticas, como o granizo (PEREIRA et al., 2012; SOUZA et al., 2015).

A manutenção da integridade foliar é importante, pois a folha é o principal órgão responsável pela fotossíntese (REZENDE et al., 2015); além disso, a cultura apresenta baixa capacidade de compensar as perdas foliares, já que sua prolificidade, capacidade efetiva de compensação de espaços e plasticidade foliar, é reduzida (PEREIRA et al., 2012). De acordo com BISCARO et al. (2013) se o objetivo é aumentar a produção de grãos, a necessidade nutricional das plantas é um fator a ser considerado. A cultura do milho requer que suas exigências nutricionais sejam plenamente atendidas, em virtude da grande extração de nutrientes do solo (LOURENTE et al., 2007). O nitrogênio é um dos nutrientes que apresentam os efeitos mais expressivos no aumento da produção de grãos, na cultura do milho (QUEIROZ et al., 2011). Conforme SANGOI et al. (2014) o nitrogênio pode auxiliar na regeneração da área foliar danificada pois, atua diretamente nos meristemas da planta, estimulando a divisão celular. A adubação nitrogenada é uma prática de manejo que pode ser usada como uma estratégia para diminuir estresses ocasionados pela redução do aparato fotossintético.

Diante do exposto, o objetivo do trabalho foi avaliar o efeito da aplicação de doses crescentes de nitrogênio em cobertura como alternativa para diminuir os danos causados pelos níveis de desfolha no rendimento dos grãos de milho.

\section{MATERIAL E MÉTODOS}

O experimento foi instalado no Campus experimental do curso de agronomia da Universidade Federal de Rondônia (UNIR), localizado no município de Rolim de Moura-RO, na Amazônia ocidental. O campo experimental está localizado a $15 \mathrm{~km}$ da cidade, a uma latitude 11ㄴ8'13" Sul e a uma longitude 6148'12" Oeste, estando a uma altitude de 290 metros acima do nível do mar. O clima é tropical quente e úmido com estações de seca bem definida (junho a setembro) com chuvas intensas nos meses de novembro a março. 
A precipitação média atual é de $2.250 \mathrm{~mm}$, umidade relativa do ar elevada no período chuvoso, em torno de $85 \%$. As temperaturas médias mínimas são de $24^{\circ} \mathrm{C}$ e as máximas são de $32^{\circ} \mathrm{C}$ (SEDAM, 2012). Solo com as seguintes características químicas: $\mathrm{pH}$ em $\mathrm{H}_{2} \mathrm{O} 6,44 ; \mathrm{M} . \mathrm{O}, 8,36 \mathrm{~g} \mathrm{dm}^{-3} ; \mathrm{P} 1,11 \mathrm{~g} \mathrm{dm}^{-3} ; \mathrm{Na} 0,07 \mathrm{cmol} \mathrm{dm}^{-3} ; \mathrm{K}$

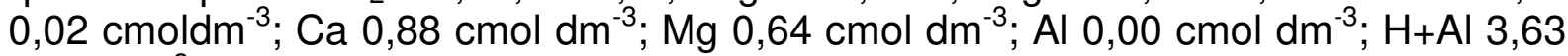
cmol dm ${ }^{-3}$; Arg. 21,0\%; Areia 43,88\%.

$O$ delineamento experimental utilizado foi o bloco casualizado, em esquema fatorial $4 \times 2$, com quatro repetições. Foram aplicadas quatro doses de adubação nitrogenada em cobertura, equivalentes a $0,60,120$ e $240 \mathrm{~kg} \mathrm{ha}^{-1}$, usando como fonte de $\mathrm{N}$ ureia $(45 \% \mathrm{~N})$ e submetendo a planta de milho a dois níveis de desfolha, remoção de $50 \%$ das folhas abaixo da espiga e remoção de $50 \%$ das folhas acima da espiga, quando as plantas estavam no estágio VT (pendoamento). A aplicação de nitrogênio foi realizada em uma única vez no período V3 (3 folhas completamente desenvolvidas), as adubações foram realizadas manualmente em filete a $10 \mathrm{~cm}$ das plantas. Por ocasião da primeira adubação nitrogenada de cobertura, aplicou-se também $42 \mathrm{~kg} \mathrm{ha}^{-1}$ de $\mathrm{K}_{2} \mathrm{O}$, usando como fonte potássica o cloreto de potássio $(60 \%$ $\left.\mathrm{K}_{2} \mathrm{O}\right)$.

O preparo da área foi de forma mecanizada, a adubação de plantio ocorreu com o auxílio de uma semeadoura, utilizando $300 \mathrm{~kg} \mathrm{ha}^{-1}$ da formulação 4-30-16, adubação de plantio conforme a análise do solo, a semeadura do milho realizou manualmente, usou-se sementes de milho safrinha hibrido $30 \mathrm{~S} 31 \mathrm{YH}$, distribuindo-se 3 sementes por metro linear, obtendo um estande de 55.000 plantas por hectare.

A parcela experimental composta por uma área de $20 \mathrm{~m}^{2}(4 \times 5 \mathrm{~m})$ com oito linhas de milho espaçadas de $0,45 \mathrm{~m}$. Sendo consideradas as quatro linhas centrais como úteis, e tendo um desconto de $1 \mathrm{~m}$ entre as extremidades, para efeito de coleta dos dados. A remoção das folhas foi realizada em todas as plantas da parcela manualmente, retirando-se as folhas verdes totalmente expandidas (com colar visível), removendo $50 \%$ das folhas acima da espiga e 50\% abaixo da espiga. Durante o experimento foram realizados todos os tratos culturais necessários para o desenvolvimento das plantas, sendo: o controle de pragas, doenças e de plantas invasoras.

Os caracteres avaliados foram:

Diâmetro da espiga: coletou-se 10 espigas das plantas da parcela útil retirouse a palha da espiga e mensurou-se no terço médio da espiga, com auxílio um paquímetro manual obtendo uma média em milímetros.

Tamanho da espiga: coletou-se 10 espigas retirando a palha e medindo-se da base a extremidade da espiga, com o auxílio de uma fita métrica, obtendo a média em centímetros.

Número de fileiras de grãos por espiga: realizou-se uma contagem do número de fileiras verdadeiras em 10 espigas de cada parcela útil, dividindo por 10 obtendose a média por espiga.

Número de grãos por fileira: realizou-se a contagem do número de grãos na fileira em 10 espigas, da extremidade basal à extremidade apical da espiga, e os resultados em unidades.

Produtividade de grãos: foi obtida pela colheita e pela debulha manual de 10 espigas da área útil de cada unidade experimental, ajustando-se a massa de grãos para umidade de $13 \%$, os resultados assim expandidos para kg.ha ${ }^{-1}$.

Os dados foram submetidos à análise de variância pelo teste $F(p \leq 0,05)$, sendo os resultados significativos foi realizada a comparação de médias, utilizando- 
se o teste de Tukey ao nível de $5 \%$ de probabilidade. Para variáveis quantitativas, ajustadas equações de regressão polinomial testando-se o modelo linear e quadrático e selecionando aquela que apresentou maior coeficiente de determinação com os dados das variáveis. As análises foram realizadas com o programa computacional Assistat 7.7®.

\section{RESULTADOS E DISCUSSÃO}

Pela análise de variância houve efeito significativo para diâmetro da espiga (D. Esp.) e produtividade (Prod.), influenciadas pela desfolha acima e abaixo da espiga. Para o tratamento de doses de nitrogênio todas as variáveis foram influenciadas, exceto o número de grãos por fileira ( $\mathrm{N}^{\circ}$. G. Fil). Houve interação significativa entre os tratamentos desfolha e doses de nitrogênio para a variável diâmetro da espiga (D. Esp.) (Tabela 1).

TABELA 1. Resumo da análise de variância para Diâmetro da espiga (D. Esp.), Comprimento da Espiga (C. Esp.), Número de fileiras da espiga (Nº Fil.), Número de grãos por fileira ( $N^{\circ}$ G. Fil.), Produtividade (Prod.), submetidas a desfolha (abaixo e acima da espiga) e diferentes doses de nitrogênio.

\begin{tabular}{|c|c|c|c|c|c|c|}
\hline \multirow{2}{*}{$\mathrm{FV}$} & \multirow{2}{*}{ GL } & \multicolumn{5}{|c|}{ Quadrados Médios } \\
\hline & & D.Esp. & C. Esp & $N^{\circ}$. Fil & $N^{\circ}$.G.Fil & Prod. \\
\hline Desfolha (DE) & 1 & $373,122^{* *}$ & $0,350^{\mathrm{ns}}$ & $0,781^{\mathrm{ns}}$ & $12,751^{\mathrm{ns}}$ & $5,278^{* *}$ \\
\hline Doses (D) & 3 & $876,570^{* *}$ & $11,027^{* *}$ & $5,302^{*}$ & $21,099^{\text {ns }}$ & $19,169^{* *}$ \\
\hline$D E \times D$ & 3 & $40,707^{\mathrm{ns}}$ & $0,070^{\text {ns }}$ & $0,283^{\mathrm{ns}}$ & $25,853^{\text {ns }}$ & $0,378^{\text {ns }}$ \\
\hline Resíduo & 24 & 10,894 & 1,001 & 1,396 & 27,517 & 0,546 \\
\hline CV (\%) & --- & 9,77 & 6,44 & 8,48 & 20,65 & 11,25 \\
\hline \multicolumn{7}{|c|}{$\begin{array}{l}\text { ns }=\text { não significativo, }{ }^{* *} e^{*} \text { significativo ao nível de } 1 \% \text { e } 5 \% \text { de probabilidade respectivamente, pel } \\
\text { teste } \mathrm{F} \text {. }\end{array}$} \\
\hline \multicolumn{7}{|c|}{$\begin{array}{l}\text { Na média das quatro doses de } \mathrm{N} \text {, a desfolha acima da espiga obteve menor } \\
\text { tro de espigas e menor produtividade, 18,36 e } 11,65 \% \text { respectivamente } \\
\text { Iradas a desfolha abaixo da espiga (Tabela } 2 \text { ). Os resultados indicam a maior } \\
\text { ância das folhas localizadas acima da espiga para estas variáveis. ALVIM et } \\
\text { 010) avaliando os efeitos de níveis de desfolhas observaram que quando } \\
\text { rrada à testemunha, a retirada das folhas acima da espiga obteve maiores } \\
\text { es em produtividade que as folhas retiradas abaixo da espiga, corroborando } \\
\text { presente trabalho. }\end{array}$} \\
\hline
\end{tabular}


TABELA 3. Efeitos da desfolha acima e abaixo da espiga no Diâmetro das Espigas e Produtividade de plantas de milho (Zea mays).

\begin{tabular}{ccc}
\hline \multirow{2}{*}{ Tratamentos } & Diâmetro de Espigas & Produtividade \\
\cline { 2 - 3 } & $(\mathrm{mm})$ & $\left(\mathrm{kg} \cdot \mathrm{ha}^{-1}\right)$ \\
\hline Desfolha abaixo da Espiga & $37,205 \mathrm{~A}$ & $6972 \mathrm{~A}$ \\
Desfolha acima da Espiga & $30,375 \mathrm{~B}$ & $6160 \mathrm{~B}$
\end{tabular}

DMS $2,41 \quad 0,54$

Médias seguidas pela mesma letra na coluna, não diferem entre si, pelo teste Tukey ao nível de 5\% de probabilidade.

De acordo com FORNASIERI FILHO (2007), cerca de 50\% dos carboidratos acumulados nos grãos de milho são provenientes das folhas localizadas no terço superior do colmo, aproximadamente $30 \%$ das folhas localizadas no terço médio e o restante das folhas distribuídas na parte basal. ALVIM et al., (2011) reforçam que a redução na produtividade em milho em relação a desfolha é em decorrência de dois principais fatores, sendo eles a localização das folhas que são retiradas das plantas e redução de área foliar fisiologicamente ativa. SANGOI et al., (2010) ainda complementam que o milho é mais suscetível à perda de área foliar fotossinteticamente ativa entre os estádios do pendoamento e espigamento do que em qualquer outra fase do ciclo.

Importante destacar que as doses de nitrogênio não obtiveram influência na desfolha abaixo e acima da espiga, pela interação não significativa. SANGOI et al., (2014b) obtiveram resultado semelhante avaliando o nitrogênio na recuperação de plantas de milho desfolhadas. Concluíram que desfolhas realizadas em VT causam grandes prejuízos à produtividade do milho que não podem ser recuperados pela aplicação de nitrogênio em cobertura; por apresentar hábito de crescimento determinado, a planta não expande novas folhas após a floração, comprometendo o enchimento de grãos, caso as folhas expostas sejam danificadas.

No entanto, as doses de nitrogênio obtiveram efeito quadrático sobre todas as variáveis, exceto para número de grãos por fileira que não obteve efeito significativo. Para diâmetro da espiga o maior valor foi alcançado com a aplicação de $205 \mathrm{~kg}$ de N.ha ${ }^{-1}$ (Figura 1A). Para a variável Comprimento da espiga, o maior valor foi obtido com a aplicação de $171 \mathrm{~kg}$ de N.ha' ${ }^{-1}$ (Figura 1B). O maior número de fileiras por espiga foi atingido com a aplicação de $139 \mathrm{~kg}$ de N.ha ${ }^{-1}$ (Figura 1C). A maior produtividade de grãos foi alcançada com a aplicação de $165 \mathrm{~kg}$ de N.ha- ${ }^{-1}$, obtendo uma produtividade de $8160 \mathrm{~kg}^{-h^{-1}}$ (Figura 1D). 
A
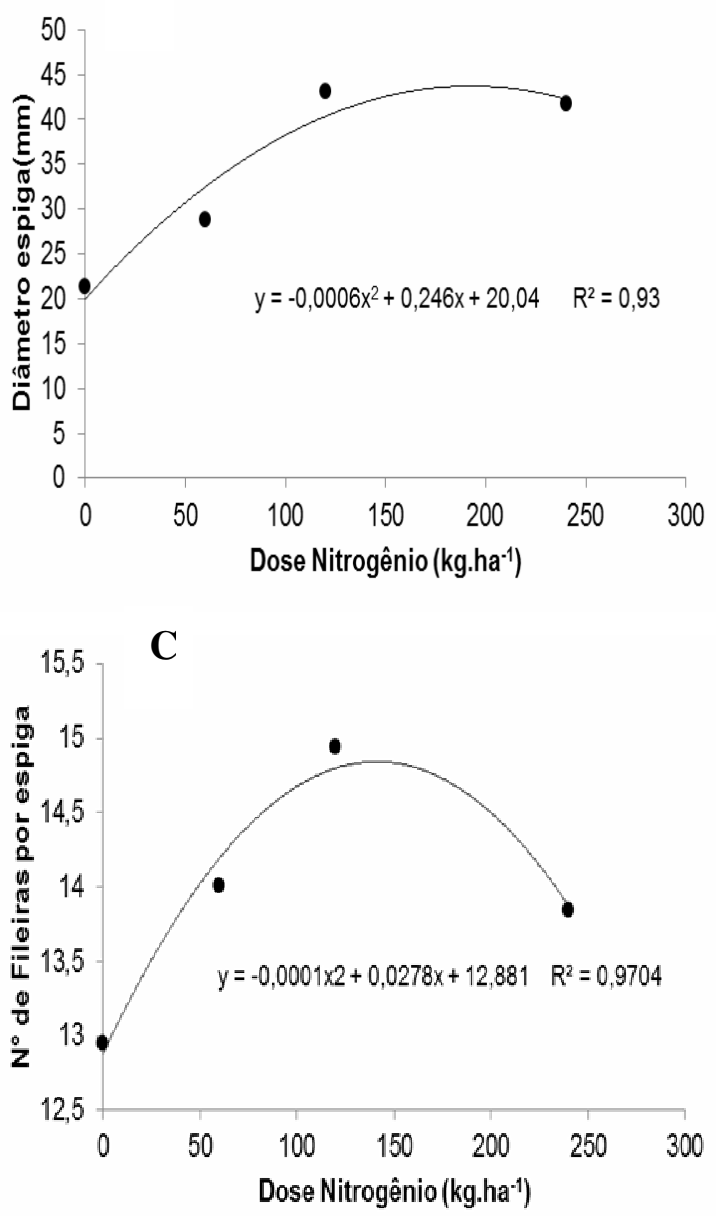

B

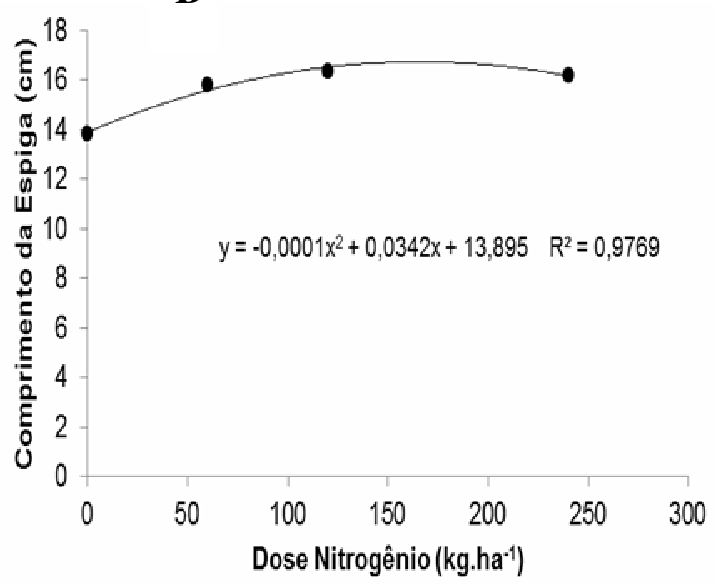

D

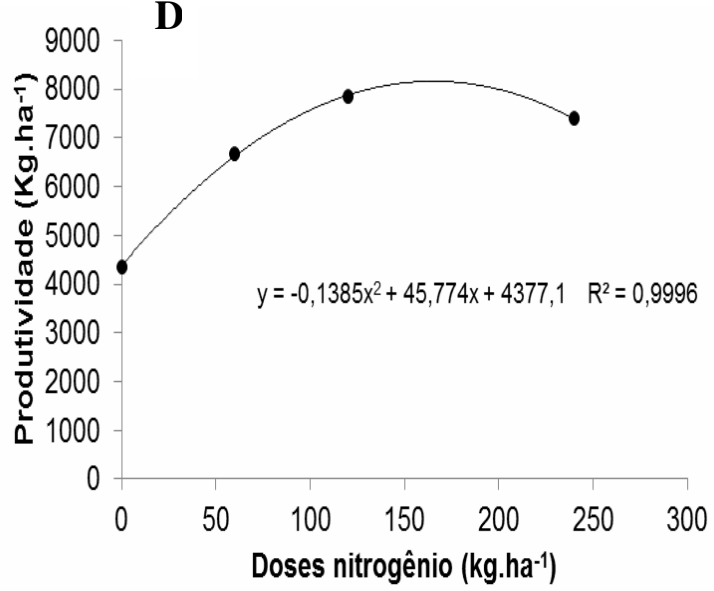

FIGURA 1. Diâmetro da espiga (A), Comprimento da espiga (B), Número de fileiras por espiga (C) e Produtividade de grãos (D), em função da aplicação de doses de nitrogênio em milho desfolhado $50 \%$ abaixo e acima da espiga.

A taxa fotossintética é influenciada pelo estado nutricional do milho, sendo que maiores taxas fotossintéticas líquidas estão diretamente relacionadas à concentração de N no tecido foliar (AITA et al., 2001).

\section{CONCLUSÃO}

A perca de área foliar acima da espiga durante o estádio de pendoamento reduz em maior escala a produtividade de grãos, demostrando maior eficiência das folhas superiores das plantas de milho para a produtividade de grãos.

As doses crescentes de nitrogênio proporcionam maiores produtividades de grãos às plantas de milho, no entanto não interferem nesta variável quando retiradas $50 \%$ das folhas abaixo ou acima da espiga.

\section{REFERÊNCIAS}

AITA, C.; BASSO, C. J.; CARETTA, C. A.; GONÇALVES, C. N.; DA ROS, C. O. Plantas de cobertura de solo como fonte de nitrogênio ao milho. Revista Brasileira de Ciência do Solo, 25:157-165, 2001. 
ALVIM, K. R. T.; BRITO, C. H.; BRANDÃO, A. M.; GOMES, L. S.; LOPES, M. T. G.; Quantificação da área foliar e efeito da desfolha em componentes de produção de milho. Ciência Rural, Santa Maria, v. 40, n. 5, p. 1017-1022, maio, 2010.

ALVIM, K. R. T.; BRITO, C. H.; BRANDÃO, A. M.; GOMES, L. S.; LOPES, M. T. G. Redução da área foliar em plantas de milho na fase reprodutiva. Revista Ceres, Viçosa, v. 58, n.4, p. 413-418, 2011.

BISCARO, G. A.; PRADO, E. A. F.; MOTOMIYA, A. V. A.; ROBAINA, A. D. Efeito de diferentes níveis de adubação foliar com NPK mais micronutrientes na produtividade do milho safrinha na Região de Dourados/MS. Semina: Ciências Agrárias, Londrina, v. 34, n. 5, p. 2169-2178, 2013. <http://dx.doi.org/10.5433/16790359.2013v34n5p2169> DOI: 10.5433/1679-0359.2013v34n5p2169.

BONO, J. A. M.; RODRIGUES, A. P. D. C.; MAUAD, M.; ALBUQUERQUE, J. C.; YAMAMOTO, C. R.; CHERMOUTH, K. S.; FREITAS, M. E. Modo de aplicação de fertilizantes nitrogenados na qualidade fisiológica de sementes de milho. Revista Agrarian, Dourados, v. 1, n. 2, p. 91-102, 2008.

CONAB - Companhia Nacional de Abastecimento. Acompanhamento da safra brasileira de grãos. Brasília: Conab, 2017. Disponível em < http://www.conab.gov.br/OlalaCMS/uploads/arquivos/17_06_08_09_02_48_boletim_ graos_junho_2017.pdf> Acessado em 1 de junho de $20 \overline{17}$.

FORNASIERI FILHO, D. Manual da cultura do milho. Jaboticabal: Funep, 2007. $576 \mathrm{p}$.

LOURENTE, E.R.P.; ONTOCELLI, R.; SOUZA, L.C.F.; GONÇALVES, M.C.; MARCHETTI, M.E. \& RODRIGUES, E.T. Culturas antecessoras, doses e fontes de nitrogênio nos componentes de produção do milho. Acta Scientiarum Agronomy, v.29, p.55-61, 2007. <http://dx.doi.org/10.4025/actasciagron.v29i1.66> DOI: 10.4025/actasciagron.v29i1.66.

PEREIRA, M.J.R.; BONAN, E.C.B.; GARCIA, A.; VASCONCELOS, R. de L.; GIACOMO, K. dos S.; LIMA, M.F. Características morfoagronômicas do milho submetido a diferentes níveis de desfolha manual. Revista Ceres, v.59, p.200 $\square 205$, 2012. <http://dx.doi.org/10.1590/S0034-737X2012000200008> DOI: 10.1590/S0034737X2012000200008.

QUEIROZ, A.M.; SOUZA, C. H. E.; MACHADO, V. J.; LANA, R. M. Q.; KORNDORFER, G. H.; SILVA.A. A. Avaliação de diferentes fontes e doses de nitrogênio na adubação da cultura do milho (zea mays l.). Revista Brasileira de Milho e Sorgo, v.10, n.3, p. 257-266, 2011. <http://dx.doi.org/10.18512/19806477/rbms.v10n3p257-266>. DOI: 10.18512/1980-6477.

REZENDE, W.S.; BRITO, C.H.; BRANDÃO, A.M.; FRANCO, C.J.F.; FERREIRA, M.V.; FERREIRA, A.S.F. Desenvolvimento e produtividade de grãos de milho submetido a níveis de desfolha. Pesquisa Agropecuária Brasileira, Brasília, v.50, 
n.3, p.203-209, 2015. <http://dx.doi.org/10.1590/S0100-204X2015000300003> DOI: 10.1590/S0100-204X2015000300003.

SANGOI, L.; PICOLI JUNIOR, G. J.; VARGAS, V. P.; VIEIRA, J.; SCHMITT, A.; ZOLDAN, S. R.; SIEGA, E.; CARNELI, G.; Cobertura nitrogenada como estratégia para reduzir os prejuízos da desfolha em diferentes estádios fenológicos do milho. Semina: Ciências Agrárias, Londrina, v. 35, n. 2, p. 671-682, mar./abr. 2014b. < http://dx.doi.org/10.5433/1679-0359.2014v35n2p671>DOI:10.5433/16790359.2014v35n2p671.

SANGOI, L.; VIEIRA, J.; SCHENATTO, D. E.; GIORDANI, W.; BONIATT, C.M.; DALLI'IGNA, L.; SOUZA, C.A.; ZANELLA, E. S. Tolerância à desfolha de genótipos de milho em diferentes estádios fenológicos. Revista Brasileira de Milho e Sorgo, v.13, n.3, p. 300-311, 2014a. <http://dx.doi.org/10.18512/19806477/rbms.v13n3p300-311> DOI: 10.18512/1980-6477.

SANGOI, L; SILVA, P. R. F.; ARGENTA, G.; RAMBO, L. Ecofisiologia da cultura do milho para altos rendimentos. Lages: Graphel, 2010. 87 p. <http://dx.doi.org/10.18512/1980-6477/rbms.v13n3p300-31> DOI: 10.18512/19806477.

SEDAM - Secretaria de Estado do Desenvolvimento Ambiental e COGEO Coordenadoria de Geociências. Boletim climatológico de Rondônia ano 2010. Porto Velho, v.12, $2012 . \quad$ Disponível <em: http://sedamro.wix.com/sedam_ro_focosqueimada\#!qualidade-do-ar.> Acessado em 10 junho. 2017.

SOUZA, V.Q.; CARVALHO, I.R.; FOLLMANN, D.N.; NARDINO, M.; BELLE, R.; BARRETO, D.; SCHMIDT, D. Desfolhamento artificial e seus efeitos nos caracteres morfológicos e produtivos em híbridos de milho. Revista Brasileira de Milho e Sorgo, v.14, n.1, p. 61-74, 2015. <http://dx.doi.org/10.18512/19806477/rbms.v14n1p61-74> DOI: 10.18512/1980-6477/rbms.v14n1p61-74. 